\title{
Personality Influences Hyperbolic Discounting
}

\author{
Sergio Da Silva ${ }^{1 *}$, Dinorá De Faveri ${ }^{1}$, Raul Matsushita ${ }^{2}$ \\ ${ }^{1}$ Department of Economics, Federal University of Santa Catarina, Florianopolis, Brazil \\ ${ }^{2}$ Department of Statistics, University of Brasilia, Brasilia, Brazil \\ Email: * professorsergiodasilva@gmail.com
}

How to cite this paper: Da Silva, S., De Faveri, D. and Matsushita, R. (2017) Personality Influences Hyperbolic Discounting. Open Access Library Journal, 4: e3998. https://doi.org/10.4236/oalib.1103998

Received: October 4, 2017

Accepted: October 23, 2017

Published: October 26, 2017

Copyright (C) 2017 by authors and Open Access Library Inc.

This work is licensed under the Creative Commons Attribution International License (CC BY 4.0).

http://creativecommons.org/licenses/by/4.0/

\begin{abstract}
We gather survey evidence for the influence of the HEXACO personality traits on the phenomenon of hyperbolic discounting. We also consider the demographics of age, sex, income and education, and evaluate how these interact with personality and hyperbolic discounting. Due to a sampling technique of "snowball", we assembled a sample of well-educated and relatively wealthy adults from both sexes. Most respondents escaped hyperbolic discounting, and for those affected there was no "magnitude effect". Those participants showing higher conscientiousness were less hyperbolic. Moreover, those more open to experience who were more extroverted at the same time were also less hyperbolic. We also detail how such personality traits influence hyperbolic discounting mediated by the demographics of age, sex, income and educational attainment. Thus, conscientiousness, openness to experience and extraversion are traits that contribute to rational decisions in intertemporal choice in our sample, in that participants with these personality traits are less hyperbolic.
\end{abstract}

\section{Subject Areas}

Behavioral Economics

\section{Keywords}

Intertemporal Choice, Hyperbolic Discounting, Impatience, Personality, HEXACO, Big Five

\section{Introduction}

As William James once observed, "There is very little difference between one man and another; but what little there is, is very important." Differences in behavior can be predicted by the personality traits of intelligence and the other Big Five: [1] [2] emotionality (E), extraversion (X), agreeableness (A), conscien- 
tiousness $(\mathrm{C})$ and openness to experience $(\mathrm{O})$. The trait of honesty-humility $(\mathrm{H})$ [3] can be added to the Big Five to make up the HEXACO model of six dimensions. The HEXACO can be assessed with reasonable validity using a 24 -item inventory [4]. Here, we are interested in assessing how the HEXACO personality traits predict economic behavior in intertemporal choice, and in particular the phenomenon of hyperbolic discounting [5]. There is survey evidence that people employ a higher rate when discounting in the short run, and thus that today's preferences differ from tomorrow's [6]. This is known as hyperbolic discounting. As for intelligence, hyperbolic discounting has been shown to be related negatively to cognitive ability [7] [8] [9] [10]. Though there is research relating the Big Five to intertemporal choice [11], there is no work relating the HEXACO traits to hyperbolic discounting. Here, we intend to fill this gap by gathering survey evidence collected using questionnaires. To assess the HEXACO, we consider the 24-item inventory of De Vries [4], and to gauge hyperbolic discounting we employ the questionnaire of Sutter et al. [12].

We also collect information from respondents regarding the demographics of age, sex, income and education, and evaluate how these interact with personality and hyperbolic discounting. In the literature, risk-taking economic behavior depends on age [13]. There is little neurological differences between 25 year olds and 75 year olds, but those below 25 years old show difficulty in accurately perceiving risks. This can be due to fact that their hormones trigger an urge to impress peers through reckless behavior. Indeed, they usually have high testosterone [14] and low monoamine oxidase levels, and these affect serotonin and mood. Hormones may thus influence their attitudes toward intertemporal choice as well as risk-taking. One individual's sex also matters for risk-taking [15] and thus possibly for intertemporal discounting, too. Moreover, income may be related to intertemporal choice mediated by cognitive processes. For instance, high-income bank customers are less hyperbolic when discounting the future [10]. Education also matters for economic behavior, and here behavioral factors may play a role [16]. Thus, educational attainment may influence hyperbolic discounting depending on personality traits.

The rest of this paper is organized as follows. Section 2 presents the materials and methods used. Section 3 shows the results found and contrasts them with the literature. Section 4 concludes the study.

\section{Materials and Methods}

We gauge hyperbolic discounting through a questionnaire [12] where respondents are asked to choose between two sure payoffs at two distinct points in time: an early payoff and a later payoff. The participants are presented eight choice lists, each containing 10 questions. In a list, the early payoff remains the same and the later payoff increases monotonically (Figure 1). The lists differ by the size of the stake of the early payoff (either 100 or 250) and by the timing of the early and late payoffs (Figure 2). Participants are shown the eight lists in Figure 1 in a random order. 


\section{List 1}

[1] receive $\$ 100$ now () or () receive $\$ 100$ in 3 weeks

[2] receive $\$ 100$ now () or () receive $\$ 105$ in 3 weeks

[3] receive $\$ 100$ now () or () receive $\$ 110$ in 3 weeks

$[10]$ receive $\$ 100$ now () or () receive $\$ 145$ in 3 weeks

\section{List 2}

[11] receive $\$ 100$ in 3 weeks () or () receive $\$ 100$ in 6 weeks

[12] receive $\$ 100$ in 3 weeks () or () receive $\$ 105$ in 6 weeks

[13] receive $\$ 100$ in 3 weeks () or () receive $\$ 110$ in 6 weeks

$[20]$ receive $\$ 100$ in 3 weeks () or () receive $\$ 145$ in 6 weeks

\section{List 3}

[21] receive $\$ 100$ now ( ) or () receive $\$ 100$ in 1 year

[22] receive $\$ 100$ now () or () receive $\$ 105$ in 1 year

[23] receive $\$ 100$ now ( ) or () receive $\$ 110$ in 1 year

$[30]$ receive $\$ 100$ now ( ) or ( ) receive $\$ 145$ in 1 year

\section{List 4}

[31] receive $\$ 100$ in 3 weeks () or () receive $\$ 110$ in 1 year and 3 weeks

[32] receive $\$ 100$ in 3 weeks () or () receive $\$ 105$ in 1 year and 3 weeks

[33] receive $\$ 100$ in 3 weeks () or () receive $\$ 110$ in 1 year and 3 weeks

$[40]$ receive $\$ 100$ in 3 weeks () or () receive $\$ 145$ in 1 year and 3 weeks

\section{List 5}

[41] receive $\$ 250$ now ( ) or ( ) receive $\$ 250$ in 3 weeks

[42] receive $\$ 250$ now () or () receive $\$ 275$ in 3 weeks

[43] receive $\$ 250$ now () or () receive $\$ 300$ in 3 weeks

$[50]$ receive $\$ 250$ now ( ) or ( ) receive $\$ 475$ in 3 weeks

Figure 1. Choice lists for gauging hyperbolic discounting. Adapted from Sutter et al. [12].
List 7
[61] receive $\$ 250$ now () or ( ) receive $\$ 250$ in 1 year
[62] receive $\$ 250$ now () or () receive $\$ 275$ in 1 year
[63] receive $\$ 250$ now ( ) or ( ) receive $\$ 300$ in 1 year
$[70]$ receive $\$ 250$ now () or () receive $\$ 475$ in 1 year

List 8

[71] receive $\$ 250$ in 3 weeks ( ) or () receive $\$ 250$ in 1 year and 3 weeks [72] receive $\$ 250$ in 3 weeks () or () receive $\$ 275$ in 1 year and 3 weeks [73] receive $\$ 250$ in 3 weeks () or () receive $\$ 300$ in 1 year and 3 weeks

$[80]$ receive $\$ 250$ in 3 weeks ( ) or ( ) receive $\$ 475$ in 1 year and 3 weeks

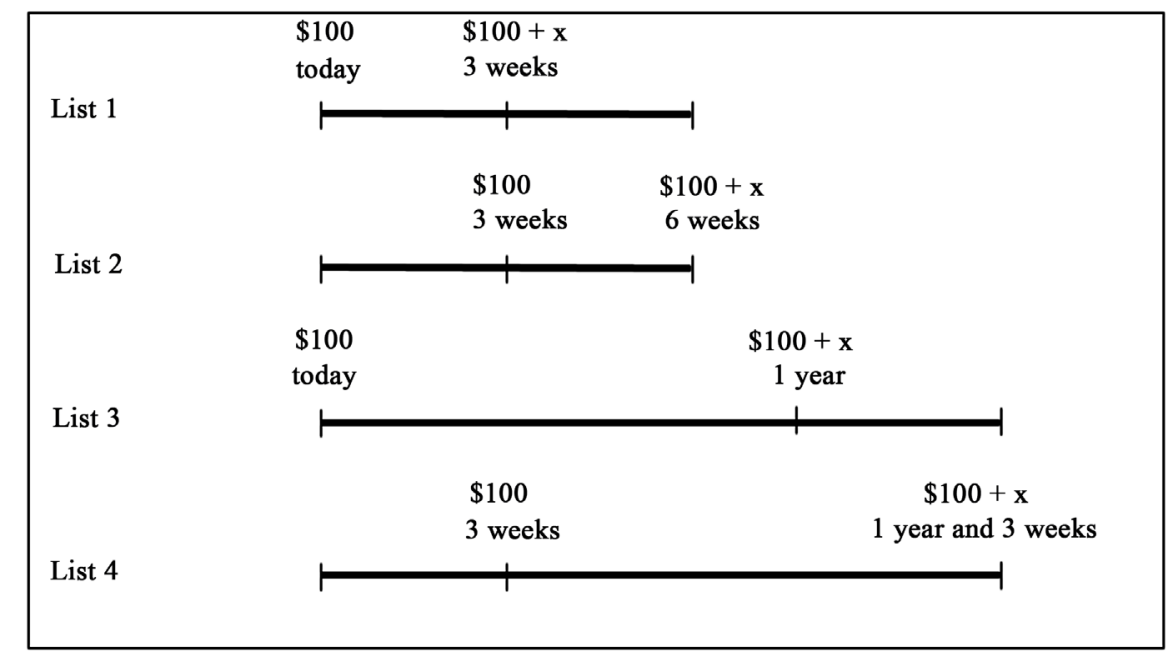

Figure 2. Combinations of early and late payoffs in four lists for a sure payoff of 100 . Adapted from Sutter et al. [12].

We calculate the "future equivalent" of the fixed early payoff from the eight lists as the midpoint between the two later payoffs, where a respondent switches from the earlier to the later payoff. Figure 3 shows how to compute the future equivalent for List 1 . The participant chose the payoff today twice (left-side option) and then switched to the right-side option. This means her future equivalent was $\$ 107.50$, that is, $(\$ 105.00+\$ 110.00) / 2$. The larger the future equivalent, the stronger the delay aversion and impatience.

Of note, Lists 1 and 2 refer to the identical delays of three weeks with an upfront delay of zero and three weeks, respectively. In Lists 3 and 4 the delay is one year, and the upfront delay is zero and three weeks, respectively. To learn whether 


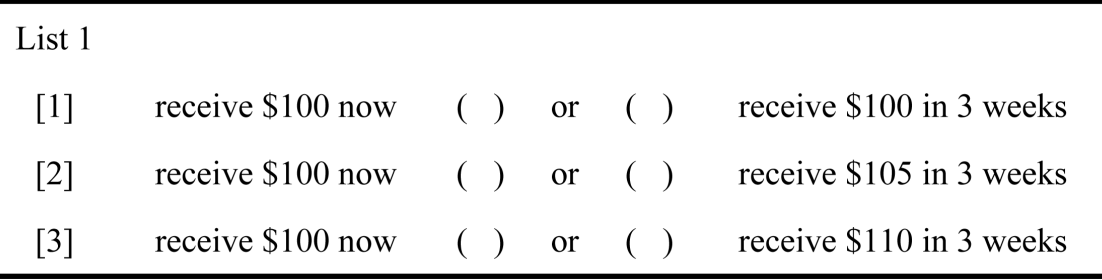

Figure 3. Example of how to calculate the future equivalent for List 1. Adapted from Sutter et al. [12].

discounting is constant or not, we compare the future equivalents between such lists. If future equivalents are higher for List 1 than for List 2, and for List 3 than for List 4, the early payoff receives more weight than the payoff in three weeks. This would provide evidence of hyperbolic discounting. We can further control for the effects of stake size by considering these four timing combinations for both high and low stakes.

After computing the future equivalents of each list in Figure 1, the lists can be compared in pairs. Considering the delays (three weeks or one year) and the stakes (100 or 250), four types of hyperbolic discounting can thus be tracked (Table 1). If the future equivalent in List 1 is, say, greater than that in List 2, this means the early payoff is weighted more than the payoff in three weeks. This would reveal a hyperbolic discounting of Type 1. Comparing Lists 3 and 4 yields a Type- 2 hyperbolic discounting, and so on.

From the computation of future equivalents for the eight lists, we can calculate “implicit annual discount rates" [12], $i$, as $i=\ln$ (future equivalent/early payoff), for a one-year delay (assuming continuous discounting), and

$i=\ln$ (future equivalent/early payoff $)(52 / 3)$, for the delay of three weeks, as a year has 52 weeks.

As observed, we gauged the personality traits of the participants through the Brief HEXACO Inventory (BHI) of De Vries [4]. This questionnaire assesses the traits randomly using a direct Likert scale or a reverse Likert scale (Table 2). Thus, we asked the participants to indicate to what extent they agreed with the 24 statements: 1 = strongly disagree; 2 = disagree; 3 = neither agree nor disagree; 4 = agree; 5 = strongly agree.

$\mathrm{BHI}$

1) I can look at a painting for a long time.

2) I make sure that things are in the right spot.

3) I remain unfriendly to someone who was mean to me.

4) Nobody likes talking to me.

5) I am afraid of feeling pain.

6) I find it difficult to lie.

7) I think science is boring.

8) I postpone complicated tasks as long as possible.

9) I often express criticism.

10) I easily approach strangers. 
Table 1. Types of hyperbolic discounting measured by future equivalents and considering delays and stakes.

\begin{tabular}{ccc}
\hline & \multicolumn{2}{c}{ Delay } \\
\cline { 2 - 3 } Stake & Three weeks & One year \\
\cline { 2 - 3 } Low & Type-1 hyperbolic discounting & Type-2 hyperbolic discounting \\
High & Type-3 hyperbolic discounting & Type-4 hyperbolic discounting \\
\hline
\end{tabular}

Table 2. The BHI in detail.

\begin{tabular}{|c|c|c|c|c|c|c|c|}
\hline \multirow[t]{2}{*}{ Personality trait } & \multirow{2}{*}{$\frac{\text { BHI item }}{6}$} & \multirow{2}{*}{$\begin{array}{c}\text { Main characteristic } \\
\text { Sincerity }\end{array}$} & \multicolumn{5}{|c|}{ Likert scale } \\
\hline & & & 1 & 2 & 3 & 4 & 5 \\
\hline \multirow{4}{*}{ Honesty-humility } & $12^{*}$ & Fairness & 5 & 4 & 3 & 2 & 1 \\
\hline & $18^{*}$ & Greed avoidance & 5 & 4 & 3 & 2 & 1 \\
\hline & $24^{*}$ & Modesty & 5 & 4 & 3 & 2 & 1 \\
\hline & 5 & Fearfulness & 1 & 2 & 3 & 4 & 5 \\
\hline \multirow{4}{*}{ Emotionality } & $11^{*}$ & Anxiety & 5 & 4 & 3 & 2 & 1 \\
\hline & $17^{\star}$ & Dependence & 5 & 4 & 3 & 2 & 1 \\
\hline & 23 & Sentimentality & 1 & 2 & 3 & 4 & 5 \\
\hline & $4^{*}$ & Social self-esteem & 5 & 4 & 3 & 2 & 1 \\
\hline \multirow{3}{*}{ eXtraversion } & 10 & Social boldness & 1 & 2 & 3 & 4 & 5 \\
\hline & 16 & Sociability & 1 & 2 & 3 & 4 & 5 \\
\hline & $22^{*}$ & Liveliness & 5 & 4 & 3 & 2 & 1 \\
\hline \multirow{4}{*}{ Agreeableness } & $3^{*}$ & Forgiveness & 5 & 4 & 3 & 2 & 1 \\
\hline & $9^{*}$ & Gentleness & 5 & 4 & 3 & 2 & 1 \\
\hline & 15 & Flexibility & 1 & 2 & 3 & 4 & 5 \\
\hline & 21 & Patience & 1 & 2 & 3 & 4 & 5 \\
\hline \multirow{4}{*}{ Conscientiousness } & 2 & Organization & 1 & 2 & 3 & 4 & 5 \\
\hline & $8^{*}$ & Diligence & 5 & 4 & 3 & 2 & 1 \\
\hline & 14 & Perfectionism & 1 & 2 & 3 & 4 & 5 \\
\hline & $20^{*}$ & Prudence & 5 & 4 & 3 & 2 & 1 \\
\hline \multirow{5}{*}{ Openness to experien } & 1 & Aesthetic appreciation & 1 & 2 & 3 & 4 & 5 \\
\hline & $7^{*}$ & Inquisitiveness & 5 & 4 & 3 & 2 & 1 \\
\hline & & & & & & & \\
\hline & 13 & Creativity & 1 & 2 & 3 & 4 & 5 \\
\hline & 19 & Unconventionality & 1 & 2 & 3 & 4 & 5 \\
\hline
\end{tabular}

${ }^{*}$ Measured considering a reverse Likert scale. Source: De Vries [4].

11) I worry less than others.

12) I would like to know how to make lots of money in a dishonest manner.

13) I have a lot of imagination.

14) I work very precisely. 
15) I tend to quickly agree with others.

16) I like to talk with others.

17) I can easily overcome difficulties on my own.

18) I want to be famous.

19) I like people with strange ideas.

20) I often do things without really thinking.

21) Even when I'm treated badly, I remain calm.

22) I am seldom cheerful.

23) I have to cry during sad or romantic movies.

24) I am entitled to special treatment.

The statements in the BHI refer to each personality trait randomly (second column in Table 2). Each of the six HEXACO traits is gauged by the scores in four major characteristics (third column in Table 3 ). The scores in each of the six traits are averaged through the scores in each of the four characteristics of a trait. Here, whenever a participant's trait falls below (above) the median, this trait is considered weak (strong) for the participant.

All participants were also asked whether their age was below 25, or 25 and above. This is claimed to be a useful sorting of age groups from a neural perspective, as seen. Participants also reported their monthly income in the Brazilian real, whether below 1000, between 1000 and 10,000, or above 10,000. We also asked the participants their educational attainment (primary, secondary, higher education or master's/doctorate).

The questionnaires were posted online and initially sent to a selected group of well-off participants by email, WhatsApp, Facebook and LinkedIn. Respondents were invited to resend the link to others. Thus, we gathered data in a snowball fashion. After a pilot experiment, the link was made active between 14 February 2017 and 28 March 2017. The link was visited 1,340 times by 954 users, mostly from the Brazilian state of Santa Catarina (73.14 percent). Users from the municipalities of Florianopolis and Blumenau were the most representative (19.95 and 11.85 percent, respectively). Respondents from other Brazilian states totaled 10.32 percent. From the initial 954 users, only 649 ended up answering the questionnaires in full (desistance rate of 31.97 percent). We further dropped from the sample 58 sloppy responses. Thus, the sample size ended up with 591 valid questionnaires. The field experiment was registered at Plataforma Brasil under No. 64758617.2.0000.0121. Plataforma Brasil is a Brazilian government organization that assesses the ethical proceedings of experiments that include human beings. The dataset is available at Figshare

(https://doi.org/10.6084/m9.figshare.5047690.v1).

Table 3. Reliability of the HEXACO items.

\begin{tabular}{ccccccc}
\hline Personality dimension & H & E & X & A & C & O \\
\hline Cronbach's $\alpha$ & 0.297 & 0.274 & 0.625 & 0.191 & 0.504 & 0.356 \\
\hline
\end{tabular}




\section{Results and Discussion}

The majority of the 591 participants were above 25 years old (73.4 percent), and 53 percent were males. As for income, 73.8 percent had monthly income between 1000 and 10,000, 23.2 percent had a monthly income above 10,000 and only 3 percent had a monthly income below 1000. As for educational attainment, the majority had a postgraduate education (54.3 percent), 35.4 percent had a college degree, 10.1 percent had a secondary education and only one participant ( 0.2 percent) had just a primary education. Thus, this is a sample of well-educated and relatively rich adults from both sexes. This characteristic should be the result of the snowball sampling adopted.

Figure 4 shows most respondents escaped hyperbolic discounting, a result that is in line with the literature [6] [10]. For the minority affected, comparing the hyperbolic discounting of Type 1 with Type 3, and Type 2 with Type 4, one can see there was no "magnitude effect" [17], a phenomenon that occurs when participants are sensitive not only to the relative differences in money amounts, but also to the absolute differences. A Wilcoxon signed ranks test confirmed the differences between Type 1 and Type 3 were not statistically significant $(Z=$ -0.412 based on positive ranks; asymptotic significance two-tailed $p$-value $=$ $0.680)$. The same was true of the differences between Type 2 and Type $4(\mathrm{Z}=$ $-0.457 ; p$-value $=0.647)$. This result may be due to the fact that the magnitude effect may not affect the wealthy in our sample the same way it affects everyone else.

As for the personality inventory, we first considered Cronbach's $\alpha$ reliabilities [4]. Cronbach's $\alpha \in[0,1]$ is a measure used to assess the internal consistency (reliability) of a set of test items. The internal consistency is based on the mean correlation between the items. As $\alpha \rightarrow 1$, internal consistency increases. Table 3 shows extraversion, conscientiousness and openness to experience are the items with greater reliability in our sample.

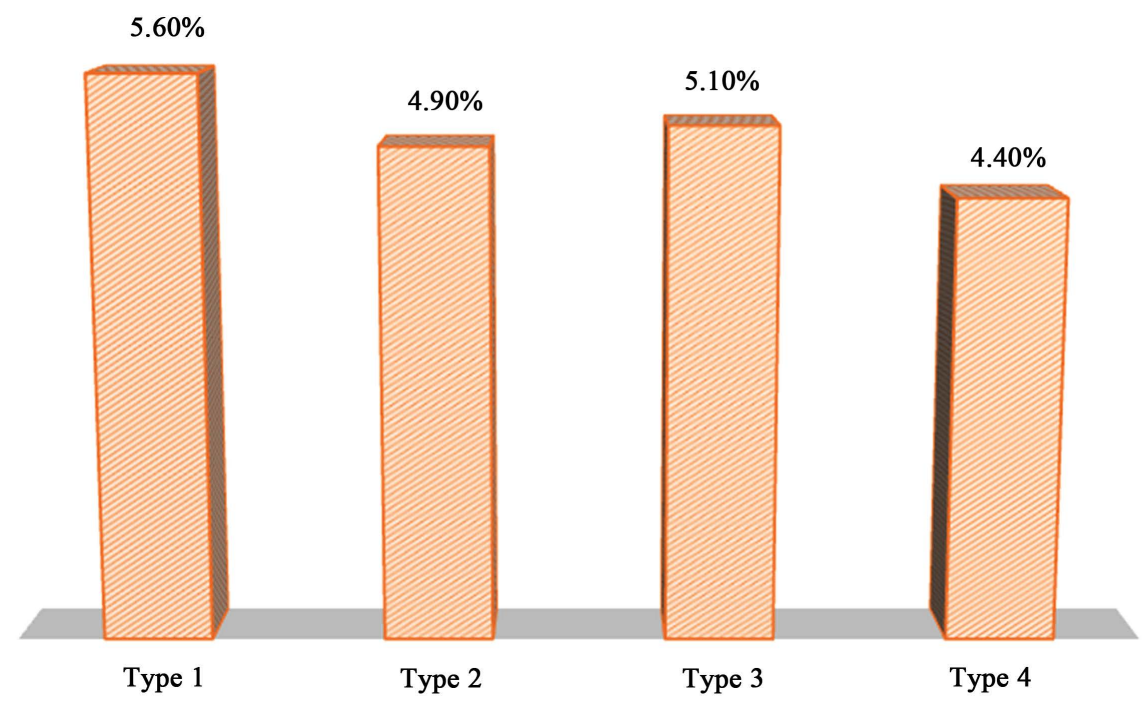

Figure 4. Incidence of hyperbolic discounting, by type. 
As for personality, we first performed a factor analysis. This method describes variability among correlated variables in terms of a potentially lower number of unobserved variables called factors. Factor analysis thus allowed us to uncover the factors that better explained a HEXACO item simultaneously. Items with low correlation with the others were then dropped from analysis. Items from a same personality dimension correlate on average 0.30 , but items from different dimensions within the same broad personality domain correlate on average 0.16 [4]. Using a correlation matrix to assess the degree of association between the items, it is then desirable to select a factor with a correlation of at least above 0.30 .

Then, we applied the Kaiser-Meyer-Olkin (KMO) test to evaluate the degree of explanation (total variance explained) from the generated factors. A KMO test showing a value above 0.5 is satisfying. The total variance explained for all the six factors combined was 49.88 percent. Using an anti-image correlation matrix (that contains the negative partial co-variances and correlations), we found the measure of sampling adequacy (MSA) that is represented by its diagonal near or above 0.5 . As a result, items $3,7,8,10,12,15$ and 23 were removed from analysis. Thus, we repeated the factor analysis and the total variance explained for all the six factors combined increased to 54.39 percent.

To maximize the explanatory power of the factors, we employed a principal component analysis, which uses an orthogonal transformation to convert a set of observations of possibly correlated variables into a set of values of linearly uncorrelated variables called principal components. In particular, we employed a varimax rotation. This is an orthogonal rotation of the factor axes to maximize the variance of the squared loadings of a factor (column) on all the variables (rows) in a factor matrix, which has the effect of differentiating the original variables by extracted factor. Table 4 shows the rotated factor matrix. Of the HEXACO, we discarded the $\mathrm{H}$ and $\mathrm{E}$. The traits of extraversion $(\mathrm{X})$, agreeableness (A), conscientiousness $(\mathrm{C})$ and openness to experience $(\mathrm{O})$ ended up properly grouped within factors $1,2,3$ and 4 , respectively. The last line in Table 4 shows the total variance explained for each factor with a $\mathrm{KMO}>0.5$.

The results from factor analysis can be used to evaluate the dependence of hyperbolic discounting on the HEXACO traits through, for instance, logistic regression.

Thus, we run binary logistic regressions by considering as dependent variables the four types of hyperbolic discounting in Table 1, plus a variable that tracked the occurrence of at least one of the four types called "hd." The independent variables were age, sex, income, educational attainment and the HEXACO traits, where a trait was represented by the mean of its related items. Employing backward regressions, one equation was first estimated including all the model variables. Whenever a variable did not contribute to improve the predictive power of the model, it was removed.

We first run a binary logistic regression with hd as the dependent variable. We found conscientiousness negatively affected hyperbolic discounting $(-0.26 ; 5$ 
Table 4. Varimax rotated factor matrix.

\begin{tabular}{|c|c|c|c|c|c|c|c|}
\hline & Item & Factor 1 & Factor 2 & Factor 3 & Factor 4 & Factor 5 & Factor 6 \\
\hline \multirow{3}{*}{$\mathrm{H}$} & 6 & 0.13 & 0.27 & 0.22 & -0.00 & 0.11 & 0.68 \\
\hline & 18 & -0.01 & 0.15 & -0.03 & -0.16 & 0.69 & -0.03 \\
\hline & 24 & -0.01 & -0.13 & 0.01 & 0.11 & 0.74 & 0.04 \\
\hline \multirow{3}{*}{$\mathrm{E}$} & 5 & -0.12 & -0.08 & -0.22 & -0.04 & -0.07 & 0.76 \\
\hline & 11 & 0.05 & 0.43 & -0.59 & -0.08 & -0.12 & 0.09 \\
\hline & 17 & -0.41 & -0.05 & -0.34 & -0.16 & 0.18 & 0.14 \\
\hline \multirow{3}{*}{$\mathrm{X}$} & 4 & 0.75 & 0.02 & 0.06 & -0.05 & -0.01 & -0.12 \\
\hline & 16 & 0.64 & -0.03 & -0.12 & 0.26 & -0.02 & 0.28 \\
\hline & 22 & 0.70 & 0.07 & 0.01 & -0.01 & 0.10 & 0.00 \\
\hline \multirow{2}{*}{ A } & 9 & 0.22 & 0.13 & 0.40 & 0.04 & 0.34 & 0.00 \\
\hline & 21 & -0.04 & 0.06 & 0.77 & -0.00 & -0.11 & 0.03 \\
\hline \multirow{3}{*}{ C } & 2 & -0.02 & 0.66 & -0.03 & 0.12 & -0.05 & 0.14 \\
\hline & 14 & 0.04 & 0.73 & -0.07 & 0.09 & 0.02 & -0.02 \\
\hline & 20 & 0.09 & 0.57 & 0.31 & -0.23 & 0.20 & -0.05 \\
\hline \multirow{3}{*}{$\mathrm{O}$} & 1 & -0.20 & 0.27 & 0.21 & 0.64 & 0.06 & 0.03 \\
\hline & 13 & 0.10 & -0.03 & -0.02 & 0.61 & -0.23 & -0.14 \\
\hline & 19 & 0.36 & -0.04 & -0.04 & 0.63 & 0.21 & 0.11 \\
\hline \multicolumn{2}{|c|}{$\begin{array}{c}\text { Total variance } \\
\text { explained }\end{array}$} & 11.9 & 10.03 & 8.72 & 4.26 & 8.04 & 7.15 \\
\hline
\end{tabular}

Notes: 1) The greatest loading for an item is in bold. 2) Items 3, 7, 8, 10, 12, 15 and 23 were previously dropped.

percent significant; Hosmer-Lemeshow test $=5.14$; Nagelkerke test $=0.53$ ) . (Hosmer-Lemeshow test assesses the goodness of fit for logistic regression models; Nagelkerke test tracks predictive power and is similar to $R$-squared.) Thus, those participants showing higher conscientiousness were less hyperbolic.

Then we considered all the four types of hyperbolic discounting (Table 5). Now openness to experience and extraversion as well as conscientiousness were found to affect hyperbolic discounting. Those showing higher conscientiousness tended to be less hyperbolic as before; in addition, those more open to experience and more extroverted at the same time were also less hyperbolic.

Our finding that higher conscientiousness is correlated negatively with hyperbolic discounting confirms the result previously found in the literature that higher conscientiousness is correlated positively with lower short-term impatience and more exponential time preferences [11]. The neural basis for this finding is that cognitive-control and reward brain regions are more activated for those showing higher conscientiousness [11].

Our finding that openness to experience is correlated negatively with hyperbolic discounting indirectly confirms a previous result that people showing do- 
Table 5. Binary logistic regressions.

\begin{tabular}{|c|c|}
\hline Independent variable & Hyperbolic discounting \\
\hline & Type 1 \\
\hline Conscientiousness & $-0.47(0.007)$ \\
\hline Hosmer-Lemeshow & $7.11(0.525)$ \\
\hline \multirow[t]{2}{*}{ Nagelkerke $R$-squared } & 0.83 \\
\hline & Type 2 \\
\hline Openness to experience & $-0.41(0.018)$ \\
\hline Hosmer-Lemeshow & $11.63(0.169)$ \\
\hline \multirow[t]{2}{*}{ Nagelkerke $R$-squared } & 0.84 \\
\hline & Type 3 \\
\hline Conscientiousness & $-0.43(0.012)$ \\
\hline Hosmer-Lemeshow & $7.31(0.504)$ \\
\hline \multirow[t]{2}{*}{ Nagelkerke $R$-squared } & 0.83 \\
\hline & Type 4 \\
\hline Openness to experience & $-0.39(0.049)$ \\
\hline Extraversion & $-0.37(0.047)$ \\
\hline Hosmer-Lemeshow & $14.83(0.063)$ \\
\hline Nagelkerke $R$-squared & 0.85 \\
\hline
\end{tabular}

Notes: 1) All $p$-values (in brackets) show significance at the five percent level. 2) Significance for the Hosmer-Lemeshow test means a $p$-value above 0.05 .

minance of this personality trait tend to pick long-term investments and are more patient [18].

In the literature, extraversion was found to predict higher discounting rates at the low end of the cognitive distribution [19]. This is not at odds with our finding that extroverted individuals were less hyperbolic. Indeed, only those extroverts who were also open to experience were less hyperbolic. And those open to experience are at the high end of the cognitive distribution [20].

Next, we assessed how personality affected hyperbolic discounting mediated by the demographic variables. As for age, those participants below 25 years old who showed higher conscientiousness were less affected by hyperbolic discounting $(-0.39, p<0.05$; Hosmer-Lemeshow $=3.75, p=0.711$; Nagelkerke $=$ $0.48 ; n=157)$. And those 25 years old or above who were more extroverted were less hyperbolic $(-0.41, p<0.05$; Hosmer-Lemeshow $=5.10, p=0.404$; Nagelkerke $=0.55 ; n=434)$. As for sex, extroverted males were less hyperbolic $(-0.37$, $p<0.05$; Hosmer-Lemeshow $=7.77, p=0.170$; Nagelkerke $=0.48 ; n=278)$ while females with higher conscientiousness were less hyperbolic $(-0.46, p<0.05$; Hosmer-Lemeshow $=2.51, p=0.775$; Nagelkerke $=0.58 ; n=313)$. As for income, those with income between 1,000 and 10,000 who showed higher conscientiousness were less hyperbolic $(-0.43, p<0.05$; Hosmer-Lemeshow $=6.23$, 
$p=0.284 ;$ Nagelkerke $=0.54 ; n=436)$. And those with income above 10,000 who were more open to experience were less hyperbolic $(-0.43, p<0.05$; Hosmer-Lemeshow $=9.31, p=0.157 ;$ Nagelkerke $=0.55 ; n=137)$. As observed, 97 percent of the participants had income falling within these two categories. As for educational attainment, we ignored the one participant with only a primary education. Extroverted postgraduates were less hyperbolic $(-0.41, p<0.05$; Hosmer-Lemeshow $=6.20, p=0.185$; Nagelkerke $=0.56 ; n=321$ ). Participants with a college degree who showed higher conscientiousness were less hyperbolic $-0.44, p<0.05 ;$ Hosmer-Lemeshow $=5.39, p=0.371$; Nagelkerke $=0.56 ; n=209$ Finally, those who had a secondary education with higher conscientiousness were less hyperbolic $(-0.30 p<0.05$; Hosmer-Lemeshow $=7.44, p=0.282$; Nagelkerke $=0.33 ; n=60)$.

\section{Conclusions}

We found evidence that personality traits influence hyperbolic discounting in a sample of 591 well-educated and relatively wealthy adults from both sexes. Most respondents escaped hyperbolic discounting, and for those affected there was no "magnitude effect." Those participants showing higher conscientiousness were less hyperbolic. Moreover, those more open to experience who were more extroverted at the same time were also less hyperbolic. We also detailed how these personality traits influenced hyperbolic discounting mediated by the demographics of age, sex, income and educational attainment. Our study suggests that conscientiousness, openness to experience and extraversion are traits that contribute to rational decisions in intertemporal choices, making individuals with such attributes more exponential and therefore less hyperbolic.

Such results are in line with the literature. Importantly, we further showed the introduction of the HEXACO as opposed to the Big Five makes no difference in our analysis because the honesty-humility trait ended up discarded.

\section{References}

[1] Goldberg, L.R. (1993) The Structure of Phenotypic Personality Traits. American Psychologist, 48, 26-34. https://doi.org/10.1037/0003-066X.48.1.26

[2] McCrae, R.R. and Costa Jr., P.T. (2004) A Contemplated Revision of the NEO Five-Factor Inventory. Personality and Individual Differences, 36, 587-596. https://doi.org/10.1016/S0191-8869(03)00118-1

[3] Ashton, M.C., Lee, K., Perugini, M., Szarota, P., De Vries, R.E., Di Blas, L., Boies, K. and De Raad, B. (2004) A Six-Factor Structure of Personality-Descriptive Adjectives: Solutions from Psycholexical Studies in Seven Languages. Journal of Personality and Social Psychology, 86, 356-366. https://doi.org/10.1037/0022-3514.86.2.356

[4] De Vries, R.W. (2013) The 24-Item Brief HEXACO Inventory (BHI). Journal of Research in Personality, 47, 871-880. https://doi.org/10.1016/j.jrp.2013.09.003

[5] Laibson, D. (1997) Golden Eggs and Hyperbolic Discounting. Quarterly Journal of Economics, 112, 443-478. https://doi.org/10.1162/003355397555253

[6] Frederick, S., Loewenstein, G. and O’Donoghue, T. (2002) Time Discounting and 
Time Preference: A critical Review. Journal of Economic Literature, 40, 351-401. https://doi.org/10.1257/jel.40.2.351

[7] Frederick, S. (2005) Cognitive Reflection and Decision Making. Journal of Economic Perspectives, 19, 25-42. https://doi.org/10.1257/089533005775196732

[8] Dohmen, T., Falk, A., Huffman, D. and Sunde, U. (2010) Are Risk Aversion and Impatience Related to Cognitive Ability? American Economic Review, 100, 12381260. https://doi.org/10.1257/aer.100.3.1238

[9] Oechssler, J., Roider, A. and Schmitz, P.W. (2009) Cognitive Abilities and Behavioral Biases. Journal of Economic Behavior \& Organization, 72, 147-152. https://doi.org/10.1016/j.jebo.2009.04.018

[10] Da Silva, S., De Faveri, D., Correa, A. and Matsushita, R. (2017) High-Income Consumers May Be Less Hyperbolic When Discounting the Future. Economics Bulletin, 37, 1421-1434.

[11] Manning, J., Hedden, T., Wickens, N., Whitfield-Gabrieli, S., Prelec, D. and Gabrieli, J.D.E. (2014) Personality Influences Temporal Discounting Preferences: Behavioral and Brain Evidence. NeuroImage, 98, 42-49.

[12] Sutter, M., Kocher, M.G., Glätzle-Rüetzler, D. and Trautmann, S.T. (2013) Impatience and Uncertainty: Experimental Decisions Predict Adolescents' Field Behavior. American Economic Review, 103, 510-531.

https://doi.org/10.1257/aer.103.1.510

[13] Moreira, B., Matsushita, R. and Da Silva, S. (2010) Risk Seeking Behavior of Preschool Children in a Gambling Task. Journal of Economic Psychology, 31, 794-801.

[14] Campbell, B.C., Dreber, A., Apicella, C.L., Eisenberg, D.T., Gray, P.B., Little, A.C., Garcia, J.R., Zamore, R.S. and Lum, J.K. (2010) Testosterone Exposure, Dopaminergic Reward, and Sensation-Seeking in Young Men. Physiology \& Behavior, 99, 451-456.

[15] Eckel, C.C. and Grossman, P.J. (2008) Men, Women and Risk Aversion: Experimental Evidence. In: Plott, C. and Smith, V., Eds., Handbook of Experimental Economics Results, Vol. 1, Elsevier, New York, 1061-1073.

[16] Koch, A., Nafziger, J. and Nielsen, H.S. (2015) Behavioral Economics of Education. Journal of Economic Behavior \& Organization, 115, 3-17.

[17] Prelec, D. and Loewenstein, G. (1991) Decision Making over Time and under Uncertainty: A Common Approach. Management Science, 37, 770-786.

https://doi.org/10.1287/mnsc.37.7.770

[18] Mayfield, C., Perdue, G. and Wooten, K. (2008) Investment Management and Personality Type. Financial Services Review, 17, 219-236.

[19] Hirsh, J.B., Morisano, D. and Peterson, J.B. (2008) Delay Discounting: Interactions between Personality and Cognitive Ability. Journal of Research in Personality, 42, 1646-1650.

[20] DeYoung, C.G., Grazioplene, R.G. and Peterson, J.B. (2012) From Madness to Genius: The Openness/Intellect Trait Domain as a Paradoxical Simplex. Journal of Research in Personality, 46, 63-78. 
Submit or recommend next manuscript to OALib Journal and we will provide best service for you:

- Publication frequency: Monthly

- 9 subject areas of science, technology and medicine

- Fair and rigorous peer-review system

- Fast publication process

- Article promotion in various social networking sites (LinkedIn, Facebook, Twitter, etc.)

- Maximum dissemination of your research work

Submit Your Paper Online: Click Here to Submit

Or Contact service@oalib.com 